\title{
PROFILE OF STUDENTS OF HIGH SCHOOL AND THEIR INTEREST ON BIOTECHNOLOGY
}

\author{
Oliveira, T.H.G.; Oliveira, M.R.G; Bossolan, N.R.S; Beltramini. L.M. \\ Centro de Biotecnologia Molecular Estrutural (CBME/CEPID/FAPESP), Instituto de \\ Física de São Carlos, USP, Brasil.
}

The Coordination of Education and Dissemination of CBME contributes to reduce the distance between the fast progress of the Biotechnology and Molecular Biology and the low understanding of the society about the concepts that involve these themes. Thus, to promote this connection in a conscious way, we compose a social-cultural profile of 84 students of high school (public and private) of São Carlos (SP) and we examine their interest on Biotechnology. Applying a written questionnaire, we obtained information about their access and use of computers, interest for science and their evaluation about the media's approach, and sources of information on these subjects. From the questionnaires, we registered that $78 \%$ of the students of the public school rarely or never participated in practical classes, and $12 \%$ ignore the existence of a laboratory in the school. In the private school the scores in these two issues are practically null. About the term "DNA", 33\% of the students of the public school answered "I don't know what is this", versus $5 \%$ in the private school. However, $82 \%$ of all the students have some understanding about the "gene", with small advantage to the private school. Regarding their interest in Biotechnology, there were few discrepancies among the two schools, being verified larger reference to the following themes: "contributions for the cure of human diseases" (44\%), "discoveries that help the human being" (25\%), "constitution and functioning of the human body" (22\%), "technological developments" (21\%) and "to produce experiments" $(20 \%)$. Therefore, the data showed us what are the most appropriate approaches to teaching the theme Biotechnology and indicated which students' deficiencies should be considered on it. 